Original investigation

Open Access

\title{
Trends in hyperlipidemia and hypertension management in type 2 diabetes patients from 1998-2004: a longitudinal observational
} study

\author{
Jacoba P Greving1, Petra Denig*1, Dick de Zeeuw ${ }^{1}$, Henk JG Bilo² and \\ Flora M Haaijer-Ruskamp ${ }^{1}$
}

\begin{abstract}
Address: ${ }^{1}$ Department of Clinical Pharmacology, University Medical Center Groningen, University of Groningen, The Netherlands and 2Department of Internal Medicine, Isala Clinics, Zwolle, The Netherlands

Email: Jacoba P Greving - j.p.greving@umcutrecht.nl; Petra Denig* - p.denig@med.umcg.nl; Dick de Zeeuw - d.de.zeeuw@med.umcg.nl; Henk JG Bilo - h.j.g.bilo@isala.nl; Flora M Haaijer-Ruskamp - f.m.haaijer-ruskamp@med.umcg.nl

* Corresponding author
\end{abstract}

Published: 20 September 2007

Cardiovascular Diabetology 2007, 6:25 doi:10.1 186/1475-2840-6-25

This article is available from: http://www.cardiab.com/content/6/1/25

(C) 2007 Greving et al; licensee BioMed Central Ltd.

This is an Open Access article distributed under the terms of the Creative Commons Attribution License (http://creativecommons.org/licenses/by/2.0), which permits unrestricted use, distribution, and reproduction in any medium, provided the original work is properly cited.

\begin{abstract}
Background: Lack of treatment initiation or intensification might explain why some patients with type 2 diabetes do not reach target goals. The objective is to assess trends in risk factor treatment, and identify determinants for medication adjustments in patients with uncontrolled hypertension and/or hyperlipidemia.
\end{abstract}

Methods: We conducted a cohort study using data from the Zwolle Outpatient Diabetes project Integrated Available Care (ZODIAC)-study in The Netherlands. Management of hypertension and hyperlipidemia was assessed yearly from 1998-2004 by measuring the percentage of patients receiving a treatment initiation or intensification among all patients with elevated risk factor levels. Generalized estimating equation analyses were performed.

Results: During the study period, the percentage of patients with an elevated total cholesterol/ high-density lipoproteins ratio (>6) decreased considerably (from $29 \%$ to $4 \%$ ) whereas the percentage of hypertensive patients decreased only slightly ( $\geq 150 / 85 \mathrm{mmHg}$; from $58 \%$ to $51 \%$ ). Initiation of lipid-lowering therapy and intensification of antihypertensive therapy was higher in more recent years. However, still two-third of patients with insufficiently controlled blood pressure in 2003 did not receive an initiation or intensification of antihypertensive treatment in the following year. Treatment changes were mainly determined by elevated levels of the corresponding risk factor. We did not observe increased initiation rates for lipid-lowering therapy in patients with both hypertension and hyperlipidemia.

Conclusion: Hypertension and hyperlipidemia management in type 2 diabetes patients has improved in the past decade but further improvement is possible. Greater effort is needed to stimulate medication adjustments in patients with insufficiently controlled hypertension and combined risk factors. 


\section{Background}

The increased incidence of cardiovascular disease (CVD) among patients with type 2 diabetes has led to increased recognition of hypertension and hyperlipidemia as important targets of therapy in addition to hyperglycemia $[1,2]$. Clinical trials in patients with type 2 diabetes convincingly demonstrated that cholesterol reduction and tight blood pressure control reduce the risk of major cardiovascular events [3-5]. Diabetes guidelines therefore advocate an intensified treatment approach aiming at all risk factors for the primary prevention of CVD [6-9].

It has been shown that although increasing numbers of diabetes mellitus patients are nowadays tested for relevant risk factors, much smaller percentages reach target goals [10-12]. These findings might be explained by low rates of medication initiation and dose adjustment in patients with elevated risk factor levels $[11,13,14]$. In addition, there are doubts that general practitioners have sufficiently implemented a multiple risk factor approach in routine practice $[15,16]$. This could also contribute to patients being undertreated. Observational studies so far, however, have focussed mainly on the influence of single elevated risk factors on treatment modifications $[11,13,14]$. Moreover, these studies have only looked at changes in drug regimes over short periods of time, not allowing for the assessment of trends. It is therefore not clear whether treatment of multiple risk factors in patients with diabetes has intensified over the past years.

The objectives of the present study were (1) to examine trends in initiation and intensification of lipid-lowering and antihypertensive drug therapy among type 2 diabetes patients, and (2) to analyze factors associated with these drug regime changes, in particular looking at combined risk factors.

\section{Methods \\ Setting}

This study was conducted as part of an ongoing longitudinal study, the Zwolle Outpatient Diabetes project Integrated Available Care (ZODIAC)-study in The Netherlands. The ZODIAC-study is a shared-care project for type 2 diabetes within the primary setting that started in 1998. Details about this project have been published previously [17]. In brief, general practitioners (GPs) are supported by diabetes specialist nurses (DSNs) for conducting the annual control of their type 2 diabetes patients. The GPs kept full responsibility for the care of these patients and remained responsible for drug prescribing and check-ups that should take place every three months. The number of participating GPs ranged from 32 in 1998 to 46 in 2004.

\section{Study subjects}

The study population represents a dynamic cohort of type 2 diabetes patients who had at least two visits in consecutive years for their annual control to a DSN between 1998 and 2004. During this period, all patients with known and newly diagnosed type 2 diabetes were included when they met the following criteria in the judgement of their GP: (1) treated exclusively in primary care; (2) no terminal illness, and (3) no severe deficits in memory and understanding.

\section{Measurements}

The annual visit to the DSN included registration of the following data: (1) medication use (general and diabetes medication) and medical history as provided by the GP and checked with the patient; (2) height, weight, blood pressure measured at the visit; and (3) laboratory values that had been measured before the visit. The laboratory measurements were glycosylated haemoglobin (HbA1c), total cholesterol (TC), high-density lipoproteins (HDL) and low-density lipoproteins (LDL). All laboratory measurements were performed in a central laboratory. Medical history included year of diabetes onset and history of myocardial infarction and/or angina pectoris. Body mass index was calculated from weight and length $\left(\mathrm{kg} / \mathrm{m}^{2}\right)$. The TC/HDL ratio was calculated from total cholesterol and HDL cholesterol.

\section{Guideline recommendations}

During the study period, the Dutch General Practitioners' guidelines recommended a combined assessment of blood pressure and lipid levels to guide treatment to patients at high risk for CVD $[6,18]$. Lipid-lowering therapy should be targeted to patients at greatest risk for CVD: i.e. patients with pre-existing CVD, patients with a (suspected) hereditary lipid disorder or patients with an estimated 10-year coronary heart disease risk larger than 25\% as based on the Framingham risk score $[6,18]$. To eliminate the need for GPs to calculate risk scores, the guidelines incorporate colour-coded risk tables to guide management for primary prevention based on a person's age, sex, smoking status, blood pressure, and TC/HDL ratio. From these tables, it can be derived that the presence of hypertension determines the need for lipid-lowering treatment in non-smoking patients with a TC/HDL ratio of 5-7, and in smoking patients with a TC/HDL ratio of 4-6. The guideline, however, also provides two simplified recommendations for the primary prevention: men aged $50-70$ years and women aged $50-75$ years should receive lipid-lowering therapy when their TC/HDL ratio is higher than 6 for non-smoking patients and when their TC/HDL ratio is higher than 5 for smoking patients [6]. Furthermore, patients with hypertension (defined as a systolic blood pressure (SBP) $\geq 150 \mathrm{mmHg}$ or a diastolic blood 
pressure $(\mathrm{DBP}) \geq 85 \mathrm{mmHg}$ ) should be treated with antihypertensive drugs $[6,19]$.

\section{Changes in drug therapy}

Using the prescribing information from reports of annual controls by the DSNs, we determined for each patient in each year whether the patient had received an initiation or intensification of drug therapy. Drug therapy was considered to have been intensified if the dose was increased or an additional drug class was added. A switch to another drug class without continuation of the original medication was not considered as an intensification of therapy, because patients could have been switched due to side effects. Trends in drug regime changes were studied over the period 1999-2004 to determine whether the GPs changed prescribing rates for lipid-lowering and antihypertensive drug therapy. Furthermore, we examined to what extent such changes in drug treatment were determined by risk factor levels measured prior to these changes.

\section{Statistical analyses}

Descriptive analyses characterize the population of type 2 diabetes patients over time, and show the frequencies of drug regime initiations and intensifications in patients with elevated risk factor levels. To identify determinants for initiation and intensification of lipid-lowering and antihypertensive drug therapy, generalized estimating equation analyses were performed using STATA 8 . With generalized estimating equation analysis, the relation between longitudinally measured variables can be studied correcting for within person correlations caused by the repeated measurements for one subject. Models were constructed for the changes in antihypertensive treatment and changes in lipid-lowering treatment, and for initiation and intensification separately. We assessed the influence of the following factors: age, gender, SBP, DBP, TC/HDL ratio and TC preceding a possible treatment change. Factors that contributed significantly $(\mathrm{p}<0.05)$ to the model were maintained in the final model (forward stepwise regression). To test a possible combined effect of blood pressure and lipid levels, an interaction term of SBP with TC/HDL ratio was included in the models. We adjusted for HbA1c, diabetes duration, history of myocardial infarction and/or angina pectoris, body mass index, and year of screening. Because initiation of lipid-lowering treatment during our study period was recommended in men younger than 70 years and women younger than 75 years, we repeated analyses for lipid-lowering therapy including only these patients. Results are presented as odds ratios (OR) with corresponding confidence intervals (CI).

\section{Results}

\section{Characteristics of the study cohort}

The study population ranged from 946 to 1485 type 2 diabetes patients over the 6-year period from 1998 to 2003 . The mean age changed slightly from 68 years in 1998 to 67 years in 2003. Women represented the majority (on average $57 \%$ ) of the study population (Table 1).

The median duration of diabetes was 5 years and remained reasonably stable over the years. Overall, 65\% of the patients was treated with oral hypoglycaemic drugs only, and 15\% received a combination of oral hypoglycaemic drugs and insulin or insulin alone. We observed an increase in the use of lipid-lowering drug treatments (from $12 \%$ to $34 \%$ ) and antihypertensive drug treatments (from $48 \%$ to $69 \%$ ) and substantial decreases in mean HbA1c, TC/HDL ratio, and systolic blood pressure values between 1998 and 2003 (Table 1).

\section{Management of hyperlipidemia}

During the study period, the percentage of patients with an elevated TC/HDL ratio (>6) decreased considerably from $29 \%(273 / 939)$ to $4 \%(59 / 1471)$ (Figure 1$)$. In $1998,9 \%(25 / 273)$ of these insufficiently controlled patients were already on lipid-lowering drug therapy, and $11 \%$ (29/273) started treatment in the following year. By 2003 , these percentages had increased to $25 \%$ (15/59) on drug therapy, and another 26\% (15/58) starting treatment in the subsequent year. Almost no dose increase or addition of a drug class occurred over the years (Figure 1).

In multivariable analyses, TC/HDL ratio, SBP, age, history of myocardial infarction and/or angina pectoris, and year of screening were predictors of subsequent initiation of

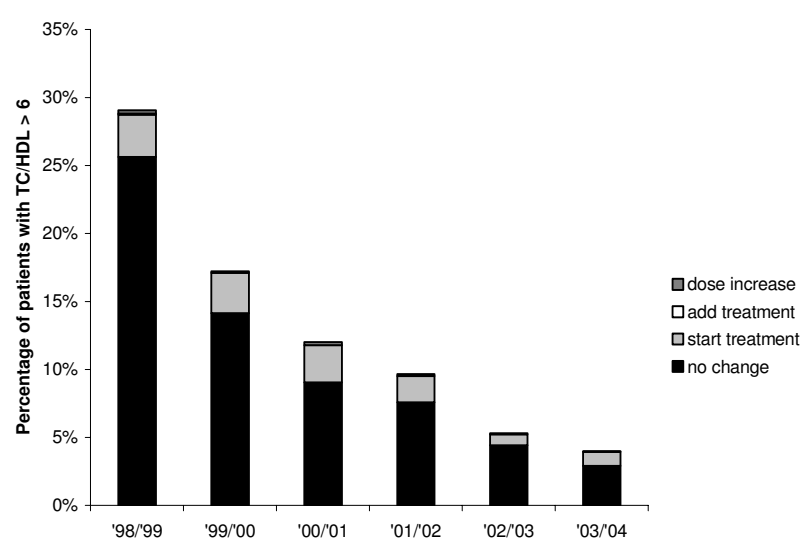

Figure I

Trends in percentages of patients with elevated TC/ HDL values and subsequent treatment modifications ( I 998-2004). TC, total cholesterol; HDL, high-density lipoprotein. 
Table I: Characteristics of type 2 diabetes patients

\begin{tabular}{|c|c|c|c|c|c|c|}
\hline & $\begin{array}{c}1998 \\
N=946\end{array}$ & $\begin{array}{c}1999 \\
N=1075\end{array}$ & $\begin{array}{c}2000 \\
N=1248\end{array}$ & $\begin{array}{c}200 I \\
N=1374\end{array}$ & $\begin{array}{c}2002 \\
N=1295\end{array}$ & $\begin{array}{c}2003 \\
N=1485\end{array}$ \\
\hline \multicolumn{7}{|l|}{ Patient characteristics } \\
\hline Age (years) & $68 \pm 11$ & $68 \pm 11$ & $67 \pm 11$ & $67 \pm 11$ & $67 \pm 11$ & $67 \pm 11$ \\
\hline Female sex (\%) & $57 \%$ & $58 \%$ & $57 \%$ & $57 \%$ & $57 \%$ & $55 \%$ \\
\hline Duration of diabetes (years) & $5(2-10)$ & $5(2-10)$ & $5(2-10)$ & $4(2-9)$ & $4(2-9)$ & $5(2-9)$ \\
\hline History of MI/AP & $25 \%$ & $22 \%$ & $21 \%$ & $19 \%$ & $18 \%$ & $18 \%$ \\
\hline Body mass index $\left(\mathrm{kg} / \mathrm{m}^{2}\right)$ & $29.0 \pm 4.7$ & $29.0 \pm 4.7$ & $29.4 \pm 4.8$ & $29.5 \pm 4.8$ & $29.5 \pm 4.7$ & $29.5 \pm 4.8$ \\
\hline HbAlc (\% units) & $7.5 \pm 1.2$ & $7.4 \pm 1.2$ & $7.3 \pm 1.3$ & $7.0 \pm 1.2$ & $7.0 \pm 1.2$ & $7.0 \pm 1.2$ \\
\hline TC/HDL ratio & $5.3 \pm 1.6$ & $4.8 \pm 1.3$ & $4.5 \pm 1.2$ & $4.4 \pm 1.2$ & $4.1 \pm 1.1$ & $3.9 \pm 1.1$ \\
\hline $\begin{array}{l}\text { Systolic blood pressure } \\
(\mathrm{mmHg})\end{array}$ & $155 \pm 25$ & $150 \pm 23$ & $150 \pm 23$ & $146 \pm 20$ & $145 \pm 2 \mid$ & $|48 \pm 2|$ \\
\hline $\begin{array}{l}\text { Diastolic blood pressure } \\
(\mathrm{mmHg})\end{array}$ & $84 \pm 11$ & $82 \pm 11$ & $81 \pm 11$ & $80 \pm 10$ & $80 \pm 10$ & $84 \pm 11$ \\
\hline \multicolumn{7}{|l|}{$\begin{array}{l}\text { Number of glucose-lowering } \\
\text { drugs }\end{array}$} \\
\hline None & $20 \%$ & $17 \%$ & $18 \%$ & $20 \%$ & $23 \%$ & $20 \%$ \\
\hline I oral & $43 \%$ & $43 \%$ & $41 \%$ & $39 \%$ & $36 \%$ & $39 \%$ \\
\hline$\geq 2$ oral & $22 \%$ & $25 \%$ & $26 \%$ & $26 \%$ & $28 \%$ & $26 \%$ \\
\hline $\begin{array}{l}\text { Insulin (with or without } \\
\text { oral drugs) }\end{array}$ & $15 \%$ & $15 \%$ & $15 \%$ & $15 \%$ & $13 \%$ & $14 \%$ \\
\hline \multicolumn{7}{|l|}{ Use of cardiovascular drugs } \\
\hline Lipid-lowering drugs & $12 \%$ & $15 \%$ & $22 \%$ & $27 \%$ & $30 \%$ & $34 \%$ \\
\hline Antihypertensive drugs & $48 \%$ & $51 \%$ & $57 \%$ & $63 \%$ & $66 \%$ & $69 \%$ \\
\hline ACE-inhibitors or ARBs & $24 \%$ & $26 \%$ & $30 \%$ & $36 \%$ & $42 \%$ & $45 \%$ \\
\hline Antiplatelet drugs & $22 \%$ & $22 \%$ & $23 \%$ & $25 \%$ & $25 \%$ & $26 \%$ \\
\hline
\end{tabular}

Values are percentages, means \pm standard deviations or median (interquartile range).

MI, myocardial infarction; AP, angina pectoris; HbAlc, haemoglobin Alc; TC, total cholesterol; HDL, high-density lipoprotein; ACE-inhibitors, angiotensin-converting enzyme inhibitors; ARBs, angiotensin II receptor blockers.

lipid-lowering therapy, while gender was not found to be associated with treatment initiation (Table 2). There was no significant interaction between TC/HDL values and SBP levels, suggesting that the association between TC/ HDL ratio and subsequent initiation of lipid-lowering therapy does not differ by SBP levels. Accordingly, we observed no difference in the proportion of patients initiated on lipid-lowering therapy who had elevated SBP levels compared to normal SBP levels (Figure 2). Only $9 \%$ of patients with SBP levels above $160 \mathrm{mmHg}$ and TC/HDL values between 5 and 6 were receiving a treatment initiation, which was not higher than for patients with similar TC/HDL values and SBP levels below $150 \mathrm{mmHg}$.

Intensification of lipid-lowering therapy was associated with TC/HDL ratio and year of screening, but not with SBP or other risk factors (Table 2). In subgroup analyses of younger patients (men aged 70 years or younger and women aged 75 years or younger), we found similar point estimates for initiation and intensification of lipid-lowering therapy, but age and SBP were not statistically significant determinants anymore. Using total cholesterol as risk factor instead of TC/HDL ratio yielded similar results (data not shown).

\section{Management of hypertension}

The percentage of hypertensive patients (SBP $\geq 150$ $\mathrm{mmHg}$ or DBP $\geq 85 \mathrm{mmHg}$ ) decreased from 58\% (544/ 930 ) in 1998 to $51 \%(754 / 1479)$ in 2003 (Figure 3). In $1998,51 \%(279 / 544)$ of the patients not reaching blood pressure targets were already on antihypertensive drug therapy, and 10\% (52/541) started treatment in the following year. By 2003, the percentage already treated had increased to $72 \%(543 / 754)$, and another $8 \%$ of patients started antihypertensive therapy (61/748). In the uncontrolled patients already on treatment, 19\% (52/276) received an intensification in 1999 and 35\% (186/539) in 2004. Adding drugs was more common than increasing the dose (Figure 3). Treatment intensifications were less likely to occur in patients taking already two antihypertensive drugs in 1998, and three or more drugs in 2003 (data not shown). The percentage of uncontrolled patients receiving no change in treatment decreased from $81 \%$ in 1998 to $67 \%$ in 2003 (black proportion of the bars in Figure 3).

In multivariable analyses, initiation of antihypertensive therapy was positively related to preceding levels of SBP, DBP, TC/HDL ratio, age, history of myocardial infarction and/or angina pectoris, and year of screening, and negatively related to HbA1c. Intensification of antihyperten- 


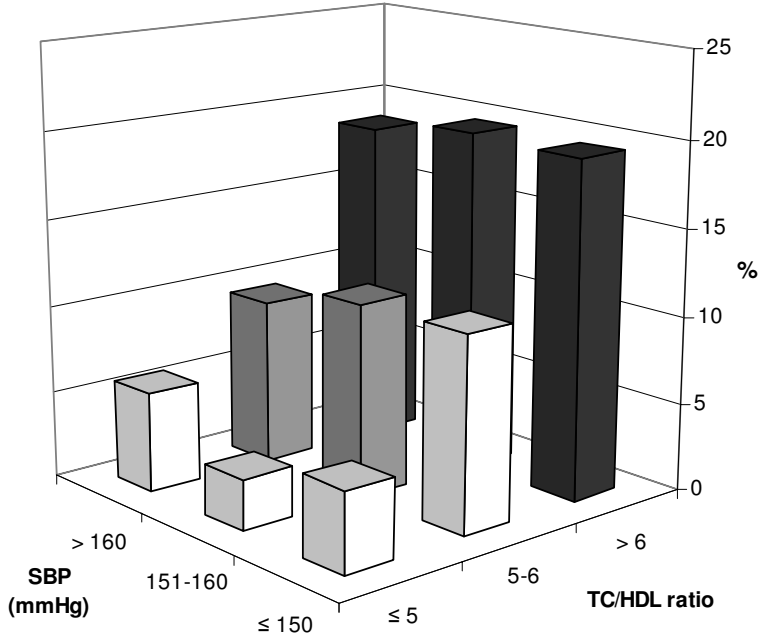

Figure 2

Percentage of patients in subgroups stratified by lipid and blood pressure levels initiated on lipid-lowering therapy. Black bars = lipid-lowering therapy recommended for most patients aged 50-70; grey bars = lipid-lowering therapy recommended for most smoking patients and males aged 60-70 years; white bars = lipid-lowering therapy seldom recommended. SBP, systolic blood pressure; TC, total cholesterol; HDL, high-density lipoprotein. sive drug therapy was positively related to SBP, DBP, age, and year of screening, but not with TC/HDL ratio or other risk factors (Table 2).

\section{Discussion}

In this large observational study, we observed an overall increased use of antihypertensive and lipid-lowering drugs, and better control of risk factors between 1998 and 2004. For lipid-lowering treatment, improvements were mainly due to an increased proportion of type 2 diabetes patients who were initiated on drug treatment, whereas for hypertension improvements especially concerned the intensification of treatment in patients already on antihypertensive therapy. In general, treatment initiations were more likely in patients with related cardiovascular comorbidity. Otherwise, treatment changes were mainly determined by elevated levels of the corresponding risk factor. We did not observe increased initiation rates of drug therapy in patients with both hypertension and hyperlipidemia. We also did not observe any gender differences regarding the initiation or intensification of drug treatment.

Despite these generally favourable improvements in the management of hyperlipidemia and hypertension, still only one-third of patients with insufficiently controlled blood pressure or lipid ratio levels in 2003 received an initiation or intensification of antihypertensive or lipid-lowering treatment in 2004. Other studies have reported similar low rates of treatment initiations, but higher rates of intensifications particularly for lipid-lowering therapy $[11,20,21]$. In a study in an US academic medical centre in 1997 to $1999,30 \%$ with elevated LDL cholesterol levels received a treatment intensification, and $30 \%$ of patients with elevated SBP levels [21]. In a Veterans Affairs study in 1998 to $1999,39 \%$ of patients with diabetes and elevated

Table 2: Multivariable analyses of factors associated with initiation and intensification of lipid-lowering and antihypertensive drug therapy

\begin{tabular}{|c|c|c|c|c|}
\hline & \multicolumn{2}{|c|}{ Lipid-lowering drug therapy } & \multicolumn{2}{|c|}{ Antihypertensive drug therapy } \\
\hline & $\begin{array}{c}\text { Initiation } \\
\text { OR*(95\% Cl) }\end{array}$ & $\begin{array}{c}\text { Intensification } \\
\mathrm{OR}(95 \% \mathrm{Cl})\end{array}$ & $\begin{array}{l}\text { Initiation } \\
\text { OR(95\% Cl) }\end{array}$ & $\begin{array}{c}\text { Intensification } \\
\text { OR }(95 \% \mathrm{Cl})\end{array}$ \\
\hline Age (per 10 years) & $0.7(0.6-0.8)$ & - & $1.2(1.1-1.3)$ & I.I (I.0-1.2) \\
\hline Gender & - & - & - & - \\
\hline HbAlc (\%) & - & - & $0.9(0.8-1.0)$ & - \\
\hline Systolic blood pressure (per $10 \mathrm{mmHg}$ ) & I.I (I.0-I.I) & - & $1.3(1.2-1.4)$ & I.I (I.I-I.2) \\
\hline Diastolic blood pressure (per $10 \mathrm{mmHg}$ ) & - & - & $1.2(1.0-1.4)$ & $1.1(1.0-1.2)$ \\
\hline $\mathrm{TC} / \mathrm{HDL}$ ratio & $1.8(1.6-1.9)$ & $1.3(1.1-1.5)$ & $1.2(1.1-1.3)$ & - \\
\hline History of MI/AP & $1.9(1.4-2.5)$ & - & $2.3(1.6-3.3)$ & - \\
\hline Year of screening & $1.3(1.2-1.4)$ & $0.9(0.8-1.0)$ & I.I (I.I-I.2) & $1.1(1.1-1.1)$ \\
\hline
\end{tabular}

* Additionally adjusted for body mass index. OR, odds ratio; HbAlc, haemoglobin AIc; TC, total cholesterol; HDL, high-density lipoprotein; MI, myocardial infarction; AP, angina pectoris. 


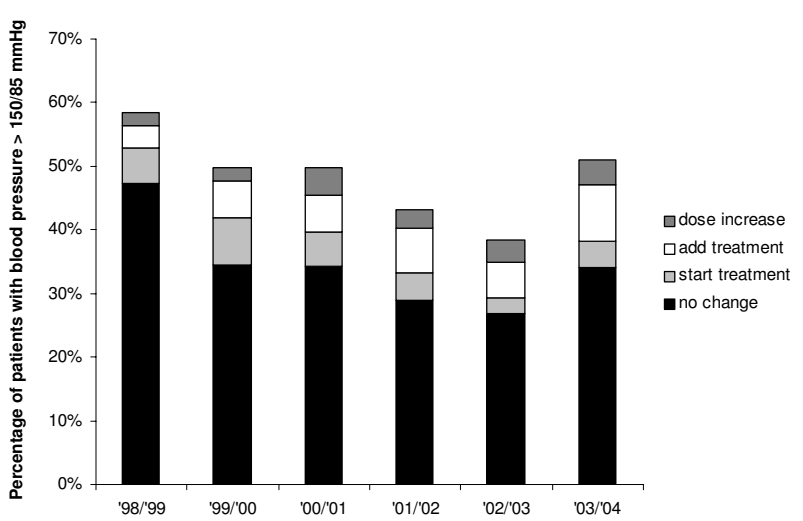

Figure 3

Trends in percentages of patients with elevated blood pressure levels and subsequent treatment modifications (I9982004).

LDL cholesterol levels received either a treatment initiation or intensification [20]. More recently, a study within a US medical care program in 2002 to 2003 showed even higher rates of therapy initiation or intensification: $64 \%$ of patients with insufficiently controlled SBP levels and $47 \%$ for insufficiently controlled LDL cholesterol levels [22]. However, their study population included all patients with hypertension, hyperlipidemia, diabetes mellitus or a combination of these conditions. It is known that patients with diabetes receive less intensive antihypertensive and lipid-lowering medication therapy than patients without diabetes [14]. Also, it should be noted that in our study, the number of patients with insufficiently controlled lipid levels was quite low in the latter years, leaving not much room for further improvement in this group of patients. The lack of gender differences suggests that disparities in quality of care measures observed in other countries regarding cardiovascular disease and diabetes management may not be that distinct in The Netherlands [23].

Several causes have been proposed why physicians may not initiate or intensify therapy [24]. Physicians may be reluctant to prescribe additional drugs because of concerns about medicalisation and poor adherence to treatment [25-27]. At the beginning of our study period, GPs were clearly less eager to intensify antihypertensive treatment in patients already receiving two or more antihypertensive drugs. Secondly, there may be barriers related to the strict high-risk approach to primary prevention. Aggressive treatment may not be beneficial or safe for all patients [28]. Although we used relatively lenient target levels for both blood pressure and lipid control in our study, some GPs may accept higher levels, especially in patient without additional cardiovascular comorbidity. It has also been suggested that the combined risk approach may be difficult to implement in routine practice. The content and format of cardiovascular risk tables have been criticized, and risk calculator use is not common $[15,16]$. We indeed observed that the percentage of lipid-lowering treatment initiations was not higher in patients with elevated blood pressure levels. According to guideline recommendations, lipid-lowering therapy is indicated in patients with high lipid ratio levels but also in patient with lower lipid ratio levels who have hypertension. Results of multivariable analyses showed that TC/HDL ratio was the strongest predictor of the initiation of lipidlowering therapy and SBP levels only had a weak effect. More importantly, there was no significant interaction between TC/HDL values and SBP levels, which suggests that the recommended combined assessment of blood pressure and lipid levels has not yet been adopted in clinical practice. Our finding that physicians primarily manage single risk factors is consistent with results from other recent studies [11,29-31].

A limitation of this study is that we evaluated the management of hyperlipidemia and hypertension within a shared-care project. Specialist nurses performed the annual control of type 2 diabetes patients which may have facilitated physicians to provide better care [17]. Specialist nurses for diabetes care are, however, common in many health care settings. Another limitation is that the data were collected on an annual basis. As a result we could not assess whether physicians responded immediately to a visit of an elevated risk factor level. Since many patients with insufficiently controlled blood pressure or lipid ratio levels did not receive a treatment initiation or intensification in the following year, our results suggests that physicians missed several opportunities to increase medication regimes or dosage. An important strength of this study is that data were collected over a long time period enabling to assess trends in treatment initiation and intensification over a 6 -year period. The average demographic characteristics and diabetes duration in our study population remained stable over these years.

\section{Conclusion}

Although our study shows that the management of hypertension and hyperlipidemia in patients with diabetes has improved in the past decade, it also demonstrates specific problems that need more attention. Physicians' readiness to start lipid-lowering therapy in patients with diabetes has increased but awareness for more intensive treatment in patients with additional hypertension appears to be lacking. In addition, the willingness to intensify antihypertensive treatment in patients with elevated blood pressure levels remains low. In the majority of treated patients no further treatment changes were made, and dosages 
were seldom increased despite uncontrolled risk factor levels.

\section{List of abbreviations used}

ACE-inhibitors- Angiotensin-converting enzyme inhibitors;

AP- Angina pectoris;

ARBs- Angiotensin II receptor blockers;

CI- Confidence intervals;

CVD- Cardiovascular disease;

DBP- Diastolic blood pressure;

DSNs- Diabetes specialist nurses;

GPs- General practitioners;

HbA1c- Haemoglobin A1c;

HDL- High-density lipoprotein;

LDL- Low-density lipoprotein;

MI- Myocardial infarction;

OR- Odds ratio;

SBP- Systolic blood pressure;

TC- Total cholesterol;

US- United States;

ZODIAC- Zwolle Outpatient Diabetes project Integrated Available Care.

\section{Competing interests}

The authors declare that they have no competing interests.

\section{Authors' contributions}

JPG and PD designed the study. JPG performed the statistical analysis. PD, DdZ, HJGB and FMH helped to interpret the results. HJGB was involved in the establishment of the database used in this study. JPG and PD led the writing of this manuscript but all listed authors contributed substantially to the editorial process and approved the final manuscript.

\section{Acknowledgements}

We would like to acknowledge the contributions of Dr. L.J. Ubink-Veltmaat and all other investigators of the ZODIAC study to this project. Special thanks to all the GPs, their assistants and the nurses specialised in diabetes who participated in the ZODIAC study for helping to collect the data.

\section{References}

I. Stamler J, Vaccaro O, Neaton JD, Wentworth D: Diabetes, other risk factors, and I2-yr cardiovascular mortality for men screened in the Multiple Risk Factor Intervention Trial. Diabetes Care 1993, 16:434-444.

2. Meigs JB, Singer DE, Sullivan LM, Dukes KA, D'Agostino RB, Nathan DM, Wagner EH, Kaplan SH, Greenfield S: Metabolic control and prevalent cardiovascular disease in non-insulin-dependent diabetes mellitus (NIDDM): The NIDDM Patient Outcome Research Team. Am J Med 1997, I02:38-47.

3. UK Prospective Diabetes Study Group: Tight blood pressure control and risk of macrovascular and microvascular complications in type 2 diabetes: UKPDS 38. BMJ 1998, 3 I 7:703-7I3.

4. Collins R, Armitage J, Parish S, Sleigh P, Peto R: MRC/BHF Heart Protection Study of cholesterol-lowering with simvastatin in 5963 people with diabetes: a randomised placebo-controlled trial. Lancet 2003, 36 I:2005-2016.

5. Gaede P, Vedel P, Larsen N, Jensen GV, Parving HH, Pedersen O: Multifactorial intervention and cardiovascular disease in patients with type 2 diabetes. N Engl J Med 2003, 348:383-393.

6. Rutten GE, Verhoeven S, Heine RJ, de Grauw WJ, Cromme PV, Reenders K, van Ballegooie E, Wiersma Tj: 'Diabetes mellitus type 2' guideline (first revision) from the Dutch College of General Practitioners. Huisarts Wet 1999, 42:67-84.

7. European Diabetes Policy Group 1999: A desktop guide to Type 2 diabetes mellitus. Diabet Med 1999, 16:716-730.

8. American Diabetes Association: Standards of medical care for patients with diabetes mellitus. Diabetes Care 2002, 25:2I 3-229.

9. Rutten GE, de Grauw WJ, Nijpels G, Goudswaard AN, Uitewaal PJ, van der Does FE, Heine RJ, van Ballegooie E, Verduijn MM, Bouma M: 'Diabetes mellitus type 2' guideline (second revision) from the Dutch College of General Practitioners. Huisarts Wet 2006, 49:137- I52.

10. Beaton SJ, Nag SS, Gunter MJ, Gleeson JM, Sajjan SS, Alexander CM: Adequacy of glycemic, lipid, and blood pressure management for patients with diabetes in a managed care setting. Diabetes Care 2004, 27:694-698.

II. Grant RW, Buse JB, Meigs JB: Quality of diabetes care in U.S. academic medical centers: low rates of medical regimen change. Diabetes Care 2005, 28:337-442.

12. Saaddine JB, Cadwell B, Gregg EW, Engelgau MM, Vinicor F, Imperatore $\mathrm{G}$, Narayan KM: Improvements in diabetes processes of care and intermediate outcomes: United States, 1988-2002. Ann Intern Med 2006, I 44:465-474.

13. Grant RW, Cagliero E, Murphy-Sheehy P, Singer DE, Nathan DM, Meigs JB: Comparison of hyperglycemia, hypertension, and hypercholesterolemia management in patients with type 2 diabetes. Am J Med 2002, I I 2:603-609.

14. Berlowitz DR, Ash AS, Hickey EC, Glickman M, Friedman R, Kader B: Hypertension management in patients with diabetes: the need for more aggressive therapy. Diabetes Care 2003, 26:355-359.

15. van Steenkiste B, van der Weijden T, Stoffers HE, Grol R: Barriers to implementing cardiovascular risk tables in routine general practice. Scand J Prim Health Care 2004, 22:32-37.

16. Eaton CB, Galliher JM, McBride PE, Bonham AJ, Kappus JA, Hickner J: Family physician's knowledge, beliefs, and self-reported practice patterns regarding hyperlipidemia: a National Research Network (NRN) survey. J Am Board Fam Med 2006, 19:46-53.

17. Ubink-Veltmaat LJ, Bilo HJ, Groenier KH, Rischen RO, Meyboom-de Jong $B$ : Shared care with task delegation to nurses for type 2 diabetes: prospective observational study. Neth J Med 2005, 63: $103-110$.

18. Thomas S, van der Weijden T, van Drenth BB, Haverkort AFM, Hooi JD, van der Laan JD: 'Cholesterol' practice guideline (first revision) from the Dutch College of General Practitioners. Huisarts Wet 1999, 42:406-417.

19. Walma EP, Grundmeijer HG, Thomas S, Prins A, van den Hoogen JP, van der Laan JR: 'Hypertension' practice guideline (second revision) from the Dutch College of general practitioners. In 
Practice guidelines for general practitioners Edited by: Geijer R, Burger J, van der Laan J. Maarssen: Elsevier/Bunge; 1999:187-205.

20. Kerr EA, Smith DM, Hogan MM, Hofer TP, Krein SL, Bermann M, Hayward RA: Building a better quality measure: are some patients with 'poor quality' actually getting good care? Med Care 2003, 41: I I73-I I82.

21. Grant RW, Cagliero E, Dubey AK, Gildesgame C, Chueh HC, Barry $M$ J, Singer DE, Nathan DM, Meigs JB: Clinical inertia in the management of type 2 diabetes metabolic risk factors. Diabet Med 2004, $21: 150-155$.

22. Rodondi N, Peng T, Karter AJ, Bauer DC, Vittinghoff E, Tang S, Pettitt $D$, Kerr EA, Selby JV: Therapy modifications in response to poorly controlled hypertension, dyslipidemia, and diabetes mellitus. Ann Intern Med 2006, I 44:475-484.

23. Bird CE, Fremont AM, Bierman AS, Wickstrom S, Shah M, Rector T, Horstman T, Escarce Jj: Does quality of care for cardiovascular disease and diabetes differ by gender for enrollees in managed care plans? Women's Health Issues 2007, I7:131-138.

24. Phillips LS, Branch WT, Cook CB, Doyle JP, El Kebbi IM, Gallina DL, Miller CD, Ziemer DC, Barnes CS: Clinical inertia. Ann Intern Med 200I, 135:825-834

25. Kedward J, Dakin L: A qualitative study of barriers to the use of statins and the implementation of coronary heart disease prevention in primary care. Br J Gen Pract 2003, 53:684-689.

26. Parnes BL, Main DS, Dickinson LM, Niebauer L, Holcomb S, Westfall JM, Pace WD: Clinical decisions regarding HbAlc results in primary care: a report from CaReNet and HPRN. Diabetes Care 2004, 27:13-16.

27. Hicks PC, Westfall JM, Van Vorst RF, Bublitz Emsermann C, Dickinson LM, Pace W, Parnes B: Action or inaction? Decision making in patients with diabetes and elevated blood pressure in primary care. Diabetes Care 2006, 29:2580-2585.

28. Hayward RA: All-or-nothing treatment targets make bad performance measures. Am J Manag Care 2007, I3(3): 126-8.

29. Wan Q, Harris MF, Jayasinghe UW, Flack J, Georgiou A, Penn DL, Burns JR: Quality of diabetes care and coronary heart disease absolute risk in patients with type 2 diabetes mellitus in Australian general practice. Qual Saf Health Care 2006, I5: I3I-I 35.

30. van Wyk JT, Picelli G, Dieleman JP, Mozafarri E, Kramarz P, van Wijk MA, van der Lei J, Sturkenboom MC: Management of hypertension and hypercholesterolaemia in primary care in The Netherlands. Curr Med Res Opin 2005, $21: 839-848$.

31. Atthobari J, Monster TB, de Jong PE, de Jong-van den Berg LT: The effect of hypertension and hypercholesterolemia screening with subsequent intervention letter on the use of blood pressure and lipid lowering drugs. Br J Clin Pharmacol 2004, 57:328-336.

Publish with Bio Med Central and every scientist can read your work free of charge

"BioMed Central will be the most significant development for disseminating the results of biomedical research in our lifetime. "

Sir Paul Nurse, Cancer Research UK

Your research papers will be:

- available free of charge to the entire biomedical community

- peer reviewed and published immediately upon acceptance

- cited in PubMed and archived on PubMed Central

- yours - you keep the copyright
BioMedcentral 